\title{
Special construction of the screw for plastics processing
}

\author{
TADEUSZ NIESZPOREK \\ PAWEK PALUTKIEWICZ \\ WŁODZIMIERZ BARANOWSKI*
}

\begin{abstract}
An innovative solution to the construction of the screw for plastics processing has been presented. The described screw is the object of the invention reported in the Polish Patent Office. It is a screw for the processing of plastics, especially the stained ones, as well as filled materials and plastics with a small difference between the plasticization and degradation temperatures. The paper discusses the characteristics of the screw and methods for its manufacturing.
\end{abstract}

\section{KEYWORDS: extrusion, plastics processing, plastics} processing screw, plasticizing

Depending on the type of production, construction of the plasticizing unit can have a decisive impact on the economic and quality results achieved. This is especially true for the production of high volume injection parts - in this case, efficiency of the plasticizing unit is important. The plasticizing system must provide an optimum homogenization of material and high plasticization efficiency. When parts that require relatively long cooling are produced, the injection molding machine normally has sufficient time reserve to carry out the dispensing phase. If the production is based on short cycles, it is important to minimize the dosing time, while maintaining good homogenization of the material. To meet these requirements, special design of plasticizing systems should be referred to (fig. 1), which provide: high plasticization efficiency, good homogenization of the material and (which often causes many problems) rapid change of colors or types of machined material [1]

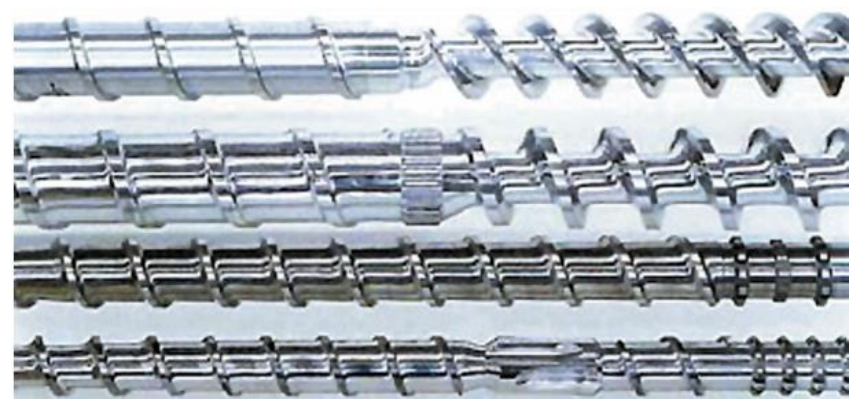

Fig. 1. Examples of unconventional screws

\author{
Specjalna konstrukcja ślimaka \\ do przetwórstwa tworzyw sztucznych
}

DOI: https://doi.org/10.17814/mechanik.2017.11.150

The problem of proper coloring the products in the case of limited plasticization time often occurs in the mass production of details made of hard-flowing polyolefins. Typically used 3-zone standard construction screws do not allow for the compatibility of quality and performance requirements. The solution may be the use of special construction screws. The tests and experiments with the use of mixing screws have confirmed their advantage over conventional screws. By using the mixing screws, [1-3] following was obtained:

- improvement of surface quality of moldings,

- better color distribution,

- uniform surface quality,

- increased plasticization efficiency, which reduced the dosing time,

- less energy consumption needed to plasticize a given portion of material,

- limiting the number of moldings discarded due to quality defects,

- reducing the number of defects that occur when changing the type or color of the injected material.

The advantages of mixing screws are particularly evident in the injection processes characterized by [1-3]:

- high dose dosage,

- the need for high rotational speed of screws,

- short cooling times.

Mixing screws (fig. 2) are used not only in processing of polyolefins, in the manufacture of packaging or household articles. Special plasticizing systems are also used in the production of technical details such as car bumpers and components of cookers or washing machines. By increasing the plasticity of the material and improving the coloration, tangible economic benefits are obtained. Mixing screws are suitable for processing a wide variety of thermoplastics.

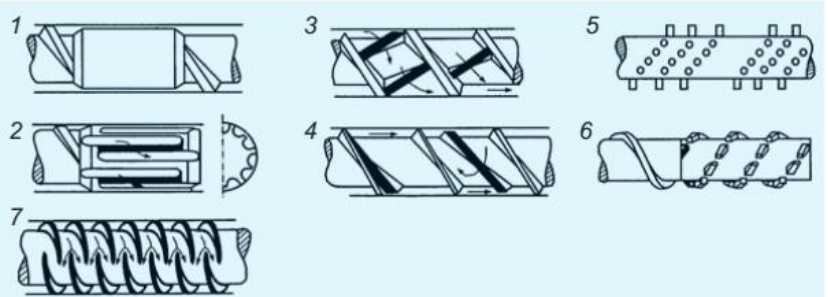

Fig. 2. Elements of intensive shear and mixing of unconventional screws: 1 - torpedo element, 2 - Maddock element, 3 - element with transverse barriers in flow channel, 4 - Maillefer element, 5 - element with mixing tabs, 6 - element with discontinuous winding, 7 - Rheotoc element $[3,4]$

\footnotetext{
* Prof. dr hab. inż. Tadeusz Nieszporek, dr inż. Pawe Palutkiewicz (palutkiewicz@ipp.pcz.pl), dr inż. Włodzimierz Baranowski - Zakład Przetwórstwa Polimerów, Instytut Technologii Mechanicznych, Wydział Inżynierii Mechanicznej i Informatyki Politechniki Częstochowskiej
}

In the case of production of moldings, which have to meet high surface quality requirements, it is a common problem to achieve a uniform coloration. The appropriate color of a detail is achieved by interacting with the 
plasticizing process or addition of larger quantities of premixtures. Both methods generate extra costs, unfortunately. In the first case, the production cycle is usually extended and the second requires the use of more expensive pre-mixtures. Mixing screws improve the coloring effect while reducing the amount of pre-mixture, lowering the plasticizing pressure and reducing the dosing time. Due to the special design of the screw, it is possible to significantly reduce the production costs and further improve the product quality. Another factor in favor of using the mixing screw is to reduce the problems associated with the change of the processed materials.

The change of color of the produced part often involved the need to spray the plasticizing systems using special cleaning materials, but inclusions or remnants of the old color appeared in the new color details. Mixing screws are designed in such a way to prevent the retention of the old material. Their design provides fast and lossless transition to a new material. Examples of construction solutions of similar screws are presented in Polish patents No. 195293 and No. 195292.

The essence of the invention [5] discussed in this paper is such a screw construction, which allows for better homogenization of stained materials and materials with fillers. On its length, the screw has a segment with a screw-shaped surface that is located in this part of the plastification system of the injection molding machine (or extruder), where a material appears in its plastic state. The purpose of this segment is to facilitate the homogenization of various materials or additives, as well as lowering the temperature and reducing the friction effect to allow processing of materials with little difference between melting point and degradation temperature. The characteristic feature of this solution is that the surface of the channel in the dispensing zone is spanned by a ball in a helical movement, and the channel surface in a cross-section perpendicular to the helical line height delimited by the center of the ball forming the channel surface, has a circular outline and the center of the wheel is located above the outer diameter of the screw.

Against the background of the well-known constructions of screws, especially with the elements of intense shear, the solution of the invention is distinguished by a special screw profile in the dispensing zone. In addition, the ductile screw surfaces of the screw coils allow for better mixing the dyed materials and materials with fillers. Special shape of the coil surface reduces friction of the material to the screw surface during processing, which lowers its temperature and thus eliminates the risk of material degradation.
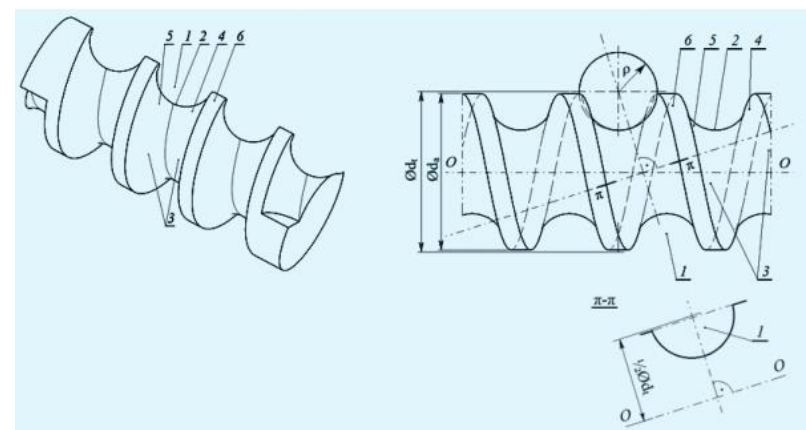

Fig. 3. Screw for material processing: 1 - screw channel, 2 screw core, 3 - side surfaces, 4 - active surface, 5 - passive surface, 6 - screw coil [5]
The screw for the plastic processing (fig. 3) has: a screw channel (1), the bottom of which is the surface of the screw core (2), and side walls (3) are formed by the active surface (4) and passive surface (5) of the screw coils (6). The surface of the channel (1) in the dispensing zone is formed by the ball helical movement, with center of the ball being outside the outer diameter of the screw. The channel (1) in the dispensing zone in a cross-section perpendicular to the helical sheave has a circular outline.

In addition, it is possible to easily make the high-shear components on the surface of the screw, namely by grooving [6]. The isometric sketch of this screw is shown in fig. 4.

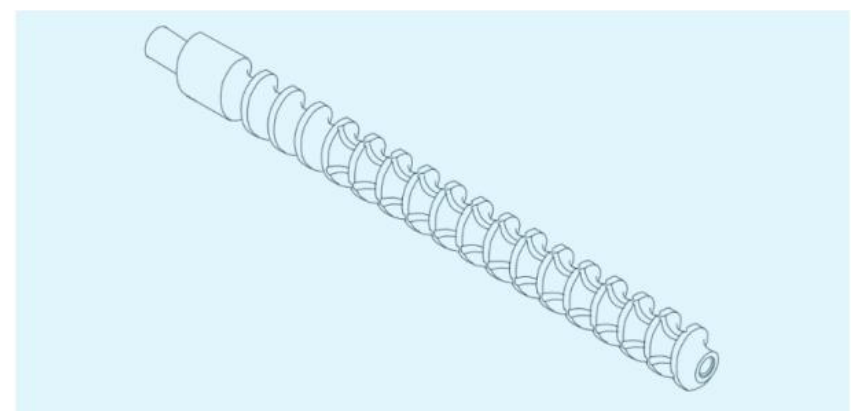

Fig. 4. Isometric view of the screw [6]

\section{Channel helical surface}

The helical surfaces are formed during a finishing work (using milling cutter or grinding wheel) by means of a rotary tool. For technological reasons (simple geometric tooling), surfaces of the screws are most often formed as helical cone-like with a tool with an axial outline of the straightening surface of the tool. Due to the specificity of the envelope processing, the surface of the tool and the machined surface have different outlines. In the case of helical cone-like surfaces, surface of the screw in any section is not straightforward, making it difficult to check the accuracy of the machining. A similar problem occurs with toroidal helical surfaces machined with a tool with circular cross-section in the axial section of the surface. Concave-convex screw gearboxes (in which the screw surface is toroidal) have better operating characteristics as compared to conventional gearboxes (cone-like screw). In plastics processing, the use of torus-shaped screws is particularly advantageous because of better mixing of the plastic in the plasticizing system of the injection molding machine or extruder. A special case of the torus-shaped helical surface is the channel helical surface, which can be shaped as an envelope of sphere group. The outline of such a surface in a characteristic cross-section is circular. Taking into account the technological conditions, the task consists in shaping the channel surface with a rotary tool, which in the general case is not a sphere.

\section{Channel helical surface shaped by means of envelope method}

The channel helical surface is generated by the ball in its helical motion. The surface obtained is the envelope of the sphere family, and the characteristic, i.e. the instantaneous contact of the ball with the helical surface, is the circle [7]. Normal lines to the characteristics intersect the center of the sphere, and normal lines to the plane of curvature are tangent to the ball center 
trajectory. The channel helical surface can also be shaped by a rotary tool with a circular cross-section in the axial section of the tool surface (grinding wheel or disc, finger, whirl, pot cutter [7-9]), twisted with respect to the axis of the helical surface so that the plane of the axial profile of the tool is perpendicular to the center of the helical line of the center movement of the tool axial profile. In the case of a fixed helical screw geometry, the distance between the center of the circular axial profile of the tool and the turning of the tool for machining the channel helical surface, depend on the radius of the circular contour of the tool. For the assumed distance of the center of the tool axis from the axis of the screw and the assumed angle of alignment of the circular contour of the tool relative to the axis of the screw, the helical pitch of any diameter (fig. 5) can be determined from the following constant stroke condition:

$$
h=2 \pi b \operatorname{tg} \beta=2 \pi r_{1} \operatorname{tg} \beta_{1}
$$

where: $h$ - helical surface pitch of the screw, $b$ - distance of the center of the circular contour of the tool from the axis of the screw, $\beta$ - angle between the normal to the plane of the circular outline of the axial tool and the axis of the screw, $r_{1}-$ split radius of the screw, $\beta_{1}-$ angle of the screw helical line on split cylinder.

It has been assumed that the axial profile of the screw is to be opened, which means that the normal to the axis of the screw intersects its outline at a single point. This is an important condition for the technology of screw machining:

$$
b \geq \frac{d_{\mathrm{a}}}{2} \Rightarrow b=b_{1} \vee b_{2}
$$

where: $d_{a}$ - outer diameter of the screw, $b$ - distance from the axis of the screw to the coordinate system origin of the contour (lower index identifies the profile).

It has been assumed that in general case, the side surfaces of the coils (lateral surfaces of the notch) may be formed as sections of 2 channel helical faces with different radii. Thus, the lateral surfaces of the screw coils may be machined by two different tools (with different axial surfaces of the tool). Equations of circular contours and normal lines to these outlines in the coordinate system of the outline (lower index identifies the coordinate system) are as follows (fig. 5):

$$
\begin{gathered}
\underset{z}{\boldsymbol{x}}(u)=\left[\begin{array}{c}
-\rho \cos u, \quad 0, \quad a+\rho \sin u
\end{array}\right]^{\mathrm{T}} \Rightarrow u \in\left\langle-\frac{\pi}{2}, \quad \frac{\pi}{2}\right\rangle, \\
a=a_{1} \vee a_{2}, \quad \rho=\rho_{1} \vee \rho_{2} \\
\boldsymbol{n}=\left[\begin{array}{lll}
-\cos u, \quad 0, \quad \sin u
\end{array}\right]^{\mathrm{T}}
\end{gathered}
$$

where: $\rho$ - radius of the axial circular tool, $u$ - parameter of the point position on the tool outline, $a$ - coordinate of the center of the circular contour of the tool in the coordinate system of the contour.

In dependence (3), there is the maximum range of $u$ parameter value in the outline for the open contours, which in the calculation for the individual cases must take into account the condition (2) for the outer diameter and the analogous condition for the diameter of the bottom of the notches:

$$
d_{\mathrm{d}} \geq(b-\rho)
$$

The specificity of the envelope processing shows that the axial profile of the helical surface is not a circle section (it is similar to a circular profile). The helical surface can be described as the envelope of the surface family of the tool's operation or as a surface described by the helical motion of the characteristics. In the first case, as shown by the theory of cutting tools and classical method of envelope determination [8], besides the equation of the surface family, it is necessary to formulate and solve the envelope condition.

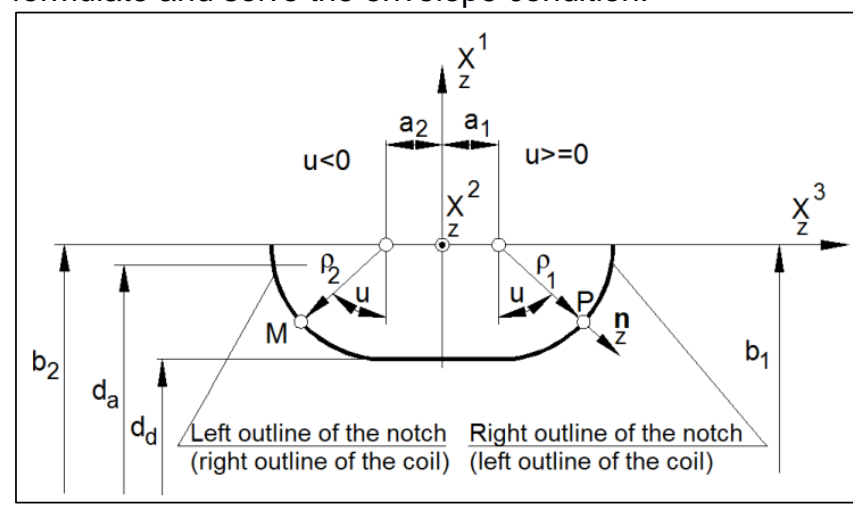

Fig. 5. Circular outline of the screw

In addition, in the first case, the type of tool and its diameter must be taken into account. The spherical tool can be considered as a special case of a finger or pot tool. Therefore, the helical surface of the screw is described using the location of the characteristics in the coordinate system of the machined screw.

The axial outline of the tool may be within the interval specified in (3), but in practice, the useful outline of the screw will be limited by the outer diameter and the diameter of the bottom of the screw notch.

Taking into account the setting and the relative helical movement of the tool (outline) in the screw coordinate system (fig. 6), the equation for the channel helical surface is as follows:

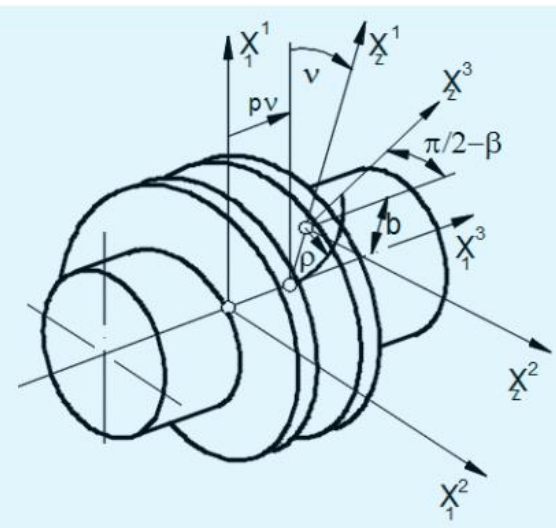

Fig. 6. Diagram of determining the channel screw surface

$$
\begin{gathered}
\underset{1}{\boldsymbol{x}}(u, v)=[3,-v]\left(\left[1,-\left(\frac{\pi}{2}-\beta\right)\right] \underset{z}{\boldsymbol{x}}+[b, 0,0]^{\mathrm{T}}\right) \pm \\
\pm\left[\begin{array}{lll}
0, & 0, & p v
\end{array}\right]^{\mathrm{T}}
\end{gathered}
$$

wherein:

$$
p=\frac{h}{2 \pi}
$$

where: $v$ - parameter of relative helical movement of circular outline of the tool and screw, $p$ - parameter of helical movement, \pm - respectively for left and right screws. 
To determine the axial outline of the helical surface of the screw, the equation (6) must be connected to the condition:

$$
x^{2}=0
$$

If for the subsequent points of the screw outline determined by values of the parameter $u$ from condition (6), values of the parameter $v$ are determined, then the normal to the axial profile of the screw at the subsequent points defined by the equation (6) can be determined from the relation:

$$
\underset{1}{n}(u, v)=[3,-v]\left[1,-\left(\frac{\pi}{2}-\beta\right)\right] \boldsymbol{n}_{z}
$$

Finally, an axial profile of the channel helical surface and normal lines to this surface at the points of its axial section were obtained. Fig. 7 shows an example of calculation results (surface parameters, axial contour coordinates) for a screw with a circular outline radius of $\rho$ $=30 \mathrm{~mm}$ in a plane directed at angle $\beta_{1}=11.31^{\circ}$ to the axis of the screw and radii from the center of the contour to the outline points in the axial plane (assumed: $\rho_{1}=\rho_{2}$ $\left.=\rho, a_{1}=a_{2}=0\right)$.

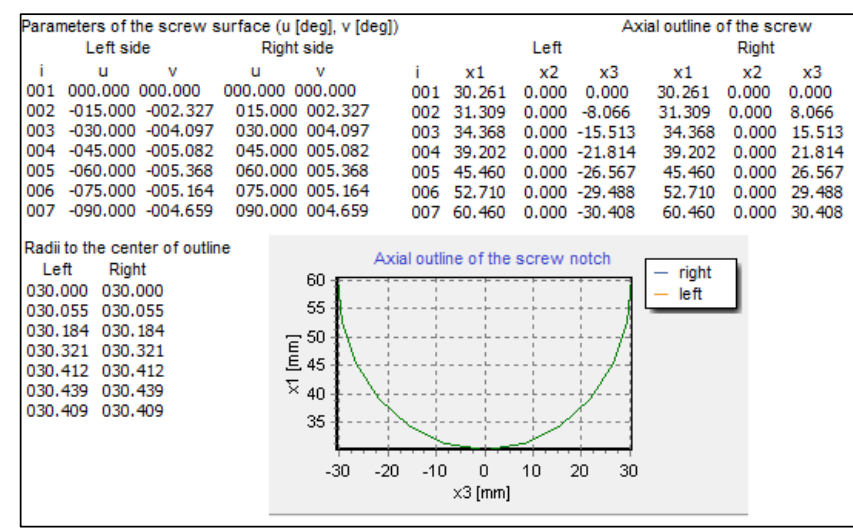

Fig. 7. Axial profile of the screw: $h=62.832, r_{1}=50, \beta_{1}=$ $11.31^{\circ}, \beta=9.422^{\circ}, b=60.261, \rho=30$

In order to develop the helical surfaces of screws, universal or special CNC numerically controlled machine tools are more and more often used. For economical (eliminating grinding) and ecological reasons (easier chip removal), milling finishing is superior to ensure the efficiency and accuracy also in the case of hardened surfaces. Making a helical surface with a tool with a circular profile in axial section with a defined radius of outline is difficult to implement. Cutters with changeable carbide or solid carbide inserts, commonly used in CNC machines, are comfortable to operate, but have complex geometry and are expensive. This applies mainly to large diameter cutters with circular contours. Therefore, in practice, machines and devices use cone-like screws that are shaped by rotary tools with an rectilinear axia outline of the tool surface. The axial contour of such screws is not straightforward, which makes it difficult to check the accuracy of their execution.

Convex-concave helical surfaces have better operating characteristics and are therefore constantly being developed and becoming more and more popular. These considerations concern shaping of the channel helical surface with a torus-like tool (with a circular outline in the axial section of the tool's operating surface) at the full height of the profile in the finishing passage. The tool can be a finger, disc, swirl or pot-shaped cutter.

Subsequently, the surface machining by a line method, which can be a competitive technology, is described.

\section{Shaping of the channel helical surface by the line method}

In this case, the helical surface of the screw is machined in many tool passages, which may be a cylindrical finger or spherical finger cutter (cylindrical or conical with a spherical tip) [10]. For technological reasons, it was decided to use a spherical finger cutter. Whereas in the classical method of envelope machining, the tool and the workpiece (their outlines) are coupled, this is different here. The tool is universal and its outline does not depend on the outline of the workpiece (screw). The tool is a finger cutter with small diameter, that is commercially available and cheap. It is important to set the tool for the next passage.

If any point of the axial profile of the screw is to be considered, in which the tool is to be tangential to the helical surface of the screw, then normal to the screw surface screw at this point should pass through the center of the cutter's sphere (spherical tip of the tool). Thus, the position of the center of the sphere for shaping the screw at a given point of its axial profile, in the coordinate system of the screw, can be determined by the equation:

$$
{\underset{N}{(S)}}^{(s} \underset{1}{\boldsymbol{x}}+\boldsymbol{r} \underset{1}{\boldsymbol{n}}
$$

where: $r$ - radius of the spherical end of the finger cutter.

By inserting the tool radii at subsequent points of the axial profile of the screw along the normal lines to the helical surface of the screw coils at these points, the coordinates of the tool center are determined at the moment of shaping the screw in its axial section. These points (center of the sphere) must be transferred by helical motion to the axial plane of the screw, and determined parameters of these points in the axial plane of the screw are the parameters of the tool setting on the CNC machine. Parameter of the helical movement (angle) to transfer these points to the axial plane of the screw, can be determined by:

$$
\psi=\operatorname{arctg} \frac{\boldsymbol{x}_{N}^{2^{2(S)}}}{\boldsymbol{x}_{N}^{1(S)}}
$$

where: $\psi$ - angle between the radius of the center of the finger cutter's sphere and the axial plane of the screw at the moment of shaping of the respective point of axial outline of the screw.

Based on the equation (6), but with respect to the radius of the center point of the cutter's sphere, the coordinates of the tool setting on the machine can be written with the equation:

$$
\boldsymbol{x}_{N}^{(N)}=[3,-\psi] \boldsymbol{x}_{N}^{(S)} \mp\left[\begin{array}{lll}
0, & 0, & p \psi
\end{array}\right]^{\mathrm{T}}=\left[\begin{array}{lll}
x, & 0, & z
\end{array}\right]^{\mathrm{T}}
$$

This equation also determines the tool setting parameters in the $X Z$ plane of the machine tool. 
The described algorithm is implemented for subsequent points along the entire height of the screw profile. If we assume that a partial helical surface is formed in one passage, the surfaces of the screw coils are the envelopes of the partial helical surfaces (the case of 2-parametric envelope [7, 8]). In practice, two side surfaces of the coils will be machined separately. Fulfillment of condition (2) gives the possibility of shaping a screw with a finger cutter on a 3-axis CNC milling machine, additionally equipped with a numerical divider (rotary table with horizontal axis) with rotation axis $A$ coupled to the control system of the machine tool.

\section{Conclusions}

The screw surface - channel helical or with circular outline in axial section - is advantageous for screws used in extruders or injection molding machines, as it ensures good homogenization of the material.

Helical surface with circular outline in characteristic cross-section is advantageous for metrological reasons (easy to check the accuracy of the screw machining).

The channel helical surface is a special case of a torus-like helical surface, i.e. surface machined with a rotary tool with circular cross-section in the axial section of the tool operating surface, at a special tool setting.

The line technology can be competitive for unit production and large module screws. At the same time, given that the tool outline is not imprinted directly on the outline of the workpiece, the contour of the workpiece can be freely modified, i.e. one tool can be used to machine different surfaces of the screws with different geometries. This technology, due to its multi-passage machining method, must be used on CNC universal machine tools.

\section{REFERENCES}

1. Zabrzewski B. „Konstrukcja ślimaka jako czynnik decydujący o jakości wypraski - ślimaki o specjalnej konstrukcji". Battenfeld Polska - materiały informacyjne, 2004.

2. Karl-Heinz Hüll „Fliegender Wechsel BarriereMischteilschnecke und Rückstromsperre für große Schussgewichte". Kunststoffe. 3 (2001).

3. Sikora R. "Leksykon naukowo-techniczny. Wprowadzenie do przetwórstwa tworzyw polimerowych". Lublin: Wadim Plast Sp.J. 2002.

4. Sikora R. „Przetwórstwo tworzyw wielkocząsteczkowych". Warszawa: Wydawnictwo Edukacyjne Zofii Dobkowskiej, 1993, pp. 223-226.

5. Baranowski W., Palutkiewicz P., Nieszporek T., Gnatowski A., Gnatowska R. Ślimak do przetwórstwa tworzyw sztucznych. Patent RP 222805.

6. Europejski Wzór Wspólnotowy: Baranowski W., Nieszporek T., Palutkiewicz P.: Narzędzia do obróbki, nr 02506618-0001.

7. Nieszporek T. „Konstrukcja narzędzi skrawających $i$ technologia walcowych uzębień zewnętrznych”. Seria monografie $\mathrm{nr}$ 265. ISBN 978-83-7193-586-2. Częstochowa: Wydawnictwo Politechniki Częstochowskiej, 2013.

8. Litvin F.L., Fuentes A. "Gear Geometry and Applied Theory”. Cambridge University Press. Cambridge, New York, Melbourne, Madrid, Cape Town, Singapore, Sao Paulo, 2004

9. Dudas I. "The Theory and Practice of Worm Gear Drives". London: Penton Press, 2000.

10. Nieszporek T. "Generating of Worm Gears of an Arbitrary Profile". Proceedings of the 11th ASME International Power Transmission and Gearing Conference (PTG) IDETC2011-48297, August 28-31, 2011, Washington, USA, pp. 53-62. 